\title{
Use of Multivariable Decision Methods in Decision of Retail Organizations
}

\author{
Eva Manová ${ }^{1}$, Janka Kopčáková ${ }^{1}$, Lenka Štofová ${ }^{1}$, \\ Jana Simonidesová ${ }^{1}$, Katarína Čulková ${ }^{2}$ \\ ${ }^{1}$ University of Economics in Bratislava, Tajovského 13, Košice, Slovakia \\ ${ }^{2}$ Technical University of Košice, Letná 9, Košice, Slovakia
}

\begin{abstract}
The contribution is orientated to the extended well-known methods of multivariable decisions with a closer specification of Saaty and TOPSIS method. The goal of the contribution is to evaluate the performance of individual operations in the chosen company from eastern Slovakia. According to the results there is obvious several operations in smaller towns, and better results are achieved in comparing with bigger towns, since the bigger towns have higher density of population. Obtained facts can be useful during managerial decisions at the increasing of demands on several bigger operations, with a goal to intensify the performance of the operations in bigger towns.
\end{abstract}

Keywords - Saaty method, Topsis method, Fuzzy AHP, ideal variant, basal variant.

\section{Introduction}

In present time managers often neglect the opinions of their clients. The client presents an integral part of the company, since purchasing goods and services with the aim to satisfy his needs, which presents the

DOI: 10.18421/TEM104-65

https://doi.org/10.18421/TEM104-65

Corresponding author: Janka Kopčáková, University of Economics in Bratislava, Tajovského 13, Košice, Slovakia.

Email: janka.kopcakova@euba.sk

Received: 21 September 2021.

Revised: 02 November 2021.

Accepted: 09 November 2021.

Published: 26 November 2021.

(c) BY-NC-ND(C) 2021 Eva Manová et al; published by UIKTEN. This work is licensed under the Creative Commons Attribution-NonCommercial-NoDerivs 4.0 License.

The article is published with Open Access at www.temjournal.com income for the company, while given goods and services are purchased mostly for monetary retribution.

This means the company is influenced also by its clients. Many authors describe the performance of the company as a positive value for the company, from which results that the higher is given positive value, the higher performance of the company. We can also understand the performance of a company as a key concept in evaluating the success of a company. Improving the company's performance also ensures better financial management. It is therefore necessary that every company evaluates its performance. The goal of the contribution is to compare performance of chosen operations in eastern Slovakia according selected methods of evaluation.

\section{Present State of Problem Solving}

There is an increasing concern from policy-makers over scanty quantitative information for effective performance analysis. Idowu et al. (2019) attempted to cover the gap in the evaluation of technical performance index, recommending that policymakers formulate upstream policies that encourage aggressive reserves growth and ensure optimal production [1]. There is a qualitative correlation between the prior working performance and the current performance of a company with the aim to optimize company activity, through a qualitative approach using non-linear multivariable regression [2]. This helps to make a better decision. In reality, the decision-makers are often facing the situation of vague cash flows and discount rates, or even uncertain durations when evaluating and selecting potential investments. Fuzzy set theory has the capability of capturing vague data and allows mathematical operations.

Sorenson and Lavelle (2008) introduced an approach for comparing the fuzzy set and probabilistic paradigms for ranking vague economic investment information when a present worth criterion is used [3]. 
In project evaluation, there is expected maximizing of net present value of the project. It is assumed that the fuzzy NPV of some projects may depend on the actual, crisp NPV of other projects and that the common realization of certain couples of projects may allow some (fuzzy) savings in the resource utilization [4]. Although engineering economic analysis offers tools and techniques for evaluating risky projects, the tools are not enough to place information system projects on a safe budget [5], and there is still a necessity to use this method for other sectors, such as small trader operations.

AHP and Saaty methods are too complicated to be applied in the revising process of the inconsistent comparison matrix or are difficult to preserve most of the original comparison information due to the use of a new pair-wise comparison matrix. To improve it, Ergu et al. (2011) proposed a simple method, which combines the theorem of matrix multiplication, vectors dot product, and the definition of consistent pair-wise comparison matrix, to identify the inconsistent elements [6]. Krejčí et al. (2017) highlighted the necessity of applying the concept of constrained fuzzy arithmetic instead of the concept of standard fuzzy arithmetic in a fuzzy extension of Analytic Hierarchy Process (AHP) [7]. Ramík and Korviny (2010) investigated the inconsistency of the pair-wise comparison matrix with fuzzy elements, introducing a new inconsistency index of a reciprocal matrix with fuzzy elements is introduced [8]. Lately Ramík (2018) investigated pairwise comparison matrices with fuzzy intervals as the matrix elements [9]. By introducing a more general notion of metric, Cavallo and D'Apuzzo (2009) provided a consistency index that is easy to compute in the additive and multiplicative cases [10]. Mazurek and Ramík (2019) showed that pair wise comparisons matrices is not appropriate [11], hence a new categorization of inconsistent matrices is proposed with respect to a satisfaction of selected logical properties. Hoang and Nguyen (2020) used Fuzzy analytic hierarchy process in the area of rural labor quality evaluation [12]. Fuzzy method is used also for evaluation of the cost of quality [13], presenting an innovative tool in the management and measurement of quality.

Wang (2019) introduced indices to measure fuzziness of triangular fuzzy judgments and row fuzziness proportionalities in a TFMPR [14]. It is, however, well known that classical ratio-scaling approaches have several problems. Therefore, Bernasconi et al. (2010) considered the AHP in the light of the modern theory of measurement based on the so-called mathematical psychology [15].

\section{Methodology}

During the research we used Saaty method for quantitative pair comparing of criteria. Thomas L. Saaty was well-known significant scientist from Pittsburg University. The main task of Saaty method is pair comparison. The method is used for the analysis and decision of tasks when authors select a variant that fills the determined goal the best. The method is used for decision supporting at various sectors of the market [16].

In 1982 the method had been extended to China since its process is compatible with Chinese processes of decision. In China Saaty method (AHP method) is extended in the education sector that offers courses for the understanding of the mentioned method. At the same time presently more and more authors published knowledge of Saaty method problematic. The ability of the method is to be adaptable to the data, as for example price, speed of supply, flexibility, which is the reasons why the method is still one of the most worldwide, used method of decision.

$$
\mathrm{S}=\left(s_{i j}\right), \text { when } i, j=1,2, \ldots, k
$$

Lomakin et al. (2017) uses most often during pair comparing scale with nine elements [17].

when $i, j,=1,2, \ldots, 9$.

Method of quantitative pair comparison uses following weights:

- $S_{i j}=1$ (equivalent),

- $S_{i j}=3$ (weak preference),

- $S_{i j}=5$ (strong preference),

- $S_{i j}=7$ (very strong preference),

- $S_{i j}=9$ (absolute preference), while values 2, 4, 6 and 8 express intermediate stages [18].

The approximate method is mainly mostly used method when the determination of the weights is made according to the geometric average of rows from Saaty matrix. The base of calculation is the calculation of geometric averages of individual rows from the matrix and radix of such sums. By normalization of geometric averages of rows, we obtain weights of individual criteria $w_{i}$. To calculate the normalized geometric average of rows from matrix, the Saaty suggestion of equation is used:

$$
w_{i}=\frac{\left(\prod_{j=1}^{k} s_{i j}\right) \frac{1}{k}}{\sum_{i=1}^{k}\left(\prod_{j=1}^{k} s_{i j}\right) \frac{1}{k}}
$$

when:

- $w_{i}$ - weight of i-criteria,

- $k$-number of criteria.

Saaty method can be calculated also by a simplified way, when equation (1) is replaced by three partial elements. 


$$
j=1,2, \ldots, k
$$

when:

- $k$ - number of individual criteria

- $s_{i j}$ - individual criteria

and

$$
R_{i}=\left(s_{i}\right)^{\frac{1}{k}}
$$

when:

- $\quad k$-number of individual criteria

$j=1,2, \ldots, k$

$$
w_{i}=\frac{R_{i}}{\sum_{i=1}^{k} R_{i}}
$$

when:

- $k$-number of individual criteria [19].

The goal of Saaty matrix is control of consistence. The main task of the method is to determine if the given matrix is consistent. In case the value is to $10 \%$, it means the value is acceptable. The matrixes that would present this percentage are consistent. In case the matrix does not achieve this value, the matrix is in misbalance during the paired comparison. Then it is necessary to calculate the index of consistence:

$$
\mathrm{CI}=\frac{\lambda_{\max -k}}{\mathrm{k}-1}
$$

when:

- $k$ - number of criteria,

- $\lambda_{\max }-$ the biggest value of the matrix

A final process of Saaty matrix is finished by calculation of the Consistency Ratio:

$$
\mathrm{CR}=\frac{C I}{\mathrm{RI}^{\prime}}
$$

$\mathrm{RI}^{\prime}$ means value, determined according to the Table 1, while the value of the Consistency Ratio has to meet condition: $\mathrm{CR} \leq 0,1$.

Table 1. Values of $R I^{\prime}$

\begin{tabular}{|c|c|c|c|c|c|}
\hline $\mathrm{N}$ & 1.00 & 2.00 & 3.00 & 4.00 & 5.00 \\
\hline $\mathrm{RI}$ & 0.00 & 0.00 & 0.58 & 0.9 & 1.12 \\
\hline $\mathrm{N}$ & 6.00 & 7.00 & 8.00 & 9.00 & 10.00 \\
\hline $\mathrm{RI}$ & 1.24 & 1.32 & 1.41 & 1.45 & 1.49 \\
\hline
\end{tabular}

Source: [21]

Saaty method for weights scheduling presents the base for decision methods, based on analytical hierarchic processes.

\section{Fuzzy Analytic Hierarchy Process}

Method AHP had been developed in 70-ties in the last Century. Thomas L. Saaty is the author of the method, therefore, the number of authors confuse the Saaty method with AHP methods, while it means one and the same method. The method had been lately developed. Presently we know the method as Fuzzy AHP. Fuzzy AHP is orientated to the organizing and analyzing of complex decisions, orientated to mathematic and psychology. It provides a complex frame during the representing individual elements, through which it evaluates alternative solutions. The method is developed gradually. In 1996 Chang determined the range analysis. The range analysis underwent critique that range analysis can have zero weight in pair comparison, which causes exclusion of given decision analysis. Similarly, in 2011 there was a possibility when fuzzy set theory determines the relationship between numerical and qualitative approaches. Fuzzy AHP determines the weights of the main indexes according to the evaluation scale to derive weights of any criteria from fuzzy pair comparing matrix:

- when $X=\left(x_{1}, x_{2}, x_{3}, \ldots . . x_{n}\right)$ - set of objects,

- $U=\left(u_{1}, u_{2}, u_{3} \ldots \ldots . u_{m}\right)$ - set of goals.

According to Fuzzy AHP any object is analyzed, and range analysis is made for any goal. Therefore $m$ in range analysis means values for any $u$, which can be recorded as: $M_{g i}^{1}, M^{2}{ }_{g i} \ldots M^{m}{ }_{g i}, i=1,2, \ldots ., n$. Here all $M_{g i}^{j}, j=1,2, . ., m$ present triangle fuzzy numbers. The value of fuzzy synthetic range in the relation to iobject can be then defined as:

$$
s_{i}=\sum_{j=1}^{m} M_{g i}^{j} \otimes\left[\sum_{i=1}^{n} \sum_{j=1}^{m} M_{g i}^{j}\right]-1
$$

The symbol $\otimes$ means an operation of fuzzy arithmetic multiplication and $\sum_{j=1}^{m} M_{g i}^{j}$ is obtained by fuzzy additive operation of values with volume $m$ for the concrete matrix. Consequently, we used the following calculation:

$$
\sum_{j=1}^{m} M_{g i}^{j}=\left(\sum_{j=1}^{m} l_{j}, \sum_{j=1}^{m} m_{j}, \sum_{j=1}^{m} u_{j}\right) .
$$

Through the given calculation, we obtain individual values of given criteria. Substitution to the initial formula means the multiplication of individual criteria values according to the calculation:

$$
\sum_{i=1}^{n} \sum_{j=1}^{m} M_{g i}^{j}=\left(\sum_{i=1}^{n} l_{j}, \sum_{i=1}^{n} m_{j}, \sum_{i=1}^{n} u_{j}\right)
$$


and at the same time multiplication according to the formula:

$$
\left[\sum_{i=1}^{n} \sum_{j=1}^{m} M_{g i}^{j}\right]-1=\left(\frac{1}{\sum_{i=1}^{n} u_{i}}, \frac{1}{\sum_{i=1}^{n} m_{i}}, \frac{1}{\sum_{i=1}^{n} l_{i}}\right)
$$

Wang (2008) determined corrected formula as follows.

$$
\begin{gathered}
{\left[\sum_{i=1}^{n} \sum_{j=1}^{m} M_{g i}^{j}\right]-1=} \\
=\left(\frac{\sum_{j=1}^{m} l_{i j}}{\sum_{j=1}^{m} l_{i j}+\sum_{k=1, k \neq 1}^{n} \sum_{j=1}^{n} u_{k j}}, \frac{\sum_{j=1}^{m} m_{i j}}{\sum_{k=1}^{n} \sum_{j=1}^{n} m_{k j}}, \frac{\sum_{j=1}^{m} u_{i j}}{\sum_{j=1}^{m} u_{i j}+\sum_{k=1, k \neq 1}^{n} \sum_{j=1}^{n} l_{k j}}\right)
\end{gathered}
$$

The last used formula is as follows:

$$
w_{i}=\frac{I_{T}^{\alpha}\left(s_{i}\right)}{\sum_{i=1}^{n} I_{T}^{\alpha}\left(s_{i}\right)}
$$

Through the mentioned formula relative weights of the determined criteria are determined. At the method, there is created matrix of pair comparison, which could present granting of triangle fuzzy point during individual pair comparisons according to the level of importance. According to the mentioned there is created a matrix of paired comparison, through which weights of individual criteria are calculated.

\section{TOPSIS Method (The Technique for Order Preference by Similarity to Ideal Solution)}

The main task of the TOPSIS method is arranging the file from all variants. According to the arranging, we can select the best variant. The method is based on the selection of the variant, which is closest to the ideal variant, but at the same time, it is a long way from the basic variant. A number of authors connect the TOPSIS method with other methods, on what basis various hybrid approaches arise:

- Ho (2008) - AHP - hybrid approaches have better performance due to the broader application and simplicity;

- Vaidya and Kumar (2006) - AHP and other techniques for support of decision;

- Kubler (2016) - methods that connect Fuzzy AHP and other methods, confirming that the connection improves the performance of total approach;

- Lima Junior et al. (2014) - comparing Fuzzy TOPSIS and Fuzzy AHP' - considering double comparing of decision criteria;

- Zeydan et al. (2011) - combined Fuzzy AHP, Fuzzy TOPSIS and DEA - for evaluation of suppliers in automotive industry;
- Celen \& Yalcin (2012) - combined Fuzzy AHP, Fuzzy TOPSIS and DEA - evaluation of performance of Turkish distributors of electric energy;

- Joshi, Banwet and Shankar (2011) - a combination of Delphi, AHP, TOPSIS - used methods for evaluation of performance for small traders of cold food [20].

Hwang and Yoon (1981) applied the first time TOPSIS method through a multivariable decision matrix according to the initial multivariable decision matrix [21]. The method consists of the following steps:

1. $A_{i j}$ means a representation of decision matrix $\mathrm{a}_{\mathrm{ij}}$, where any DMU is evaluated according to the criteria.

2. Normalized matrix $R=\left(r_{i j}\right) m x n$ consists of normalized values of any DMU, expressed as follows:

$$
\mathrm{r}_{\mathrm{ij}}=\frac{a i j}{\sqrt{\sum_{i=1}^{m} a 2 i j}} \mathrm{i}=1, \ldots, \mathrm{m} ; \mathrm{j}=1, \ldots, \mathrm{n}
$$

3. Normalized values of matrix $v_{i j}$ are calculated as follows:

$$
v_{i j}=w_{i} r_{i j}
$$

$j=1, \ldots, m ; i=1, \ldots, n$

Weighted criterion matrix would have following formula:

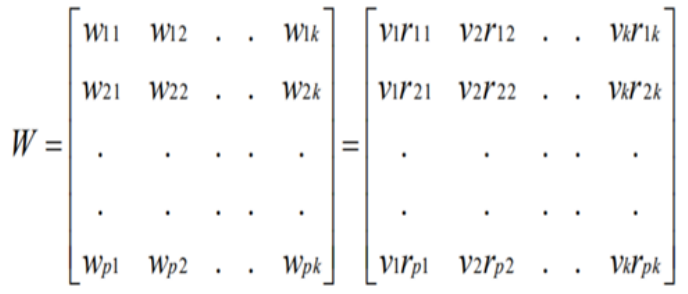

Source: [22].

4. View to the ideal: Ideal variant (positive one) $\left(A^{+}\right)$- presents the biggest contribution and the lowest costs, when $J^{\prime}$ is connected with positive impact and $J^{\prime \prime}$ is connected with negative impact.

$A+=\left\{v_{1}^{+} \ldots, v_{n}^{+}\right\}=\left\{\left(\max _{j} v_{i j} I_{j} \in J^{\prime}\right),\left(\min _{j} v_{i j} I_{j} \in J^{\prime \prime}\right)\right\}$

Basic variant (negative ideal) $\left(A^{-}\right)$- presents the lowest contribution and the highest costs.

$A^{-}=\left\{v_{1}^{-} \ldots, v_{n}^{-}\right\}=\left\{\left(\min _{j} v_{i j} I_{j} \in J^{\prime}\right),\left(\max _{j} v_{i j} I_{j} \in J^{\prime \prime}\right)\right\}$

5. Distance between ideal variant:

$$
\mathrm{d}_{i}^{+}=\sqrt{\sum_{j=1}^{n}\left(v_{i j}-v_{i}^{+}\right)} 2
$$


6. Distance between basic variant:

$$
\mathrm{d}_{i}^{-}=\sqrt{\sum_{j=1}^{n}\left(v_{i j}-v_{i}^{-}\right)} 2
$$

$i=1, \ldots, m$

Proximity of coefficient for any alternative is calculated as follows:

$$
C C_{i}=\frac{d_{i}^{-}}{d_{i}^{-}+d_{i}^{+}}
$$

TOPSIS method use with two previous methods served for obtaining of the total ranking of chosen operations. We created minimized and maximized criteria. At the beginning, we created a normalized criteria matrix. According to the matrix we calculated normalized weighted criteria matrix and we determined the ideal variant with the basic variant. After the determination of the variants, we calculated the distance between individual variants from the ideal variant and at the same time distance of the individual variant from the basic variant. Consequently, we determined the proximity of any alternative coefficient. In the frame of research, we applied obtained knowledge of the present state in practical conditions of a producer, dealing mostly with milk and milk products processing, selling in the small trade operations, registered under code SK NACE - G 47.11. The business operations of the company are placed in the area of a whole Slovak republic. The subject of the research is mostly operations in eastern Slovakia. During the research we orientated the analysis to the 16 operations in the following towns of Slovakia: P1 - Prešov, P2 Bardejov, P3 - Sabinov, P4 - Košice, P5 Giraltovce, P6 - Humenné, P7 - Kežmarok, P8 Levoča, P9 - Stará L'ubovňa, P10 - Lipany, P11 Medzilaborce, P12 - Poprad, P13 - Snina, P14 Michalovce, P15 - Svidník, P16 - Vranov and Topl'ov.

\section{Results}

Saaty method is realized according to the selected criteria. Consequently, we added preferences between individual criteria, and we determined weights for the main criteria. The selection of the criteria was chosen with an assumption of what is important for the potential clients and at the same time how the given criteria would influence the decision of the clients during the purchase in given operations. Criteria are ranged from the most important criteria to the least important one. The marking of the criteria is from $c_{1}-c_{14}$. The importance of the criteria had been determined according to the subjective estimation from the operations. The given criteria are as follows:
- $\mathrm{C}_{1}$ - quality of the product - dependent on the fact if the product is produced in Slovakia or not;

- $\mathrm{C}_{2}$ - freshness of the products - given criteria is connected mainly with milk products, fruits and vegetables;

- $\mathrm{C}_{3}$ - security of the products - given criteria deals with security of given products, if products are in warranty and if products that can be spoiled, are in hygienic and refrigerated counters;

- $\mathrm{C}_{4}$ - assortment differentiation - criteria deal with differentiation of given products in the operation and variety of the offer;

- $\mathrm{C}_{5}$ - flexibility of order to the clients' demand criteria deal with stable clients and ability of the operation to provide its clients necessary volume of the good on time in operation;

- $\mathrm{C}_{6}$ - number of clients complaints - criteria deal with percentage volume of complaints in given operation per month;

- $\mathrm{C}_{7}$ - way of service treatment - the criteria mean willingness of the service, help of the service to find proper goods, verbal communication and behavior at the cash-desk, similarly as unity of the service dress;

- $\mathrm{C}_{8}$ - cleanliness of operation - criteria present cleanliness of given operation;

- $\mathrm{C}_{9}$ - a barrier free access - criteria present possibility for a barrier free entering to the given operation also for handicapped;

- $\mathrm{C}_{10}$ - possibility to pay by card - the criteria mean possibility to pay without money in given operation;

- $\mathrm{C}_{11}$ - hygienic of the operation - the criteria illustrate observing of hygiene and cleanliness of the boxes and counters in given operation;

- $\mathrm{C}_{12}$ - the number of complaints - the criteria are determined in percentage expression per month;

- $\mathrm{C}_{13}$ - availability and transport - the criteria mean availability by city transport, similarly as a possibility to park near given operation;

- $\mathrm{C}_{14}$ - advertisement and marketing - the criteria evaluates the availability of advertisement, leaflets for potential clients in the surrounding area of the operation, or advertising billboards, etc.

Criteria weights are created according to the subjective estimation from purchase in individual operations. Weights calculation is made according to the method of quantitative pair comparison. Quantitative pair comparison is made through Saaty matrix. Values of individual pair criteria are described in Saaty matrix. There are given similar criteria in rows and columns that are ranged in a similar ranking, from which results that number 1 is in the whole diagonal. In the upper part over diagonal illustration, there are illustrated individual values in interval $\langle 1 ; 9\rangle$ to individual criteria, where 1 
(equivalent), 3 (weak preference), 5 (strong preference), 7 (very strong preference), 9 (absolute preference), while values 2, 4, 6 and 8 means intermediate levels.

Table 2. Results of Saaty matrix

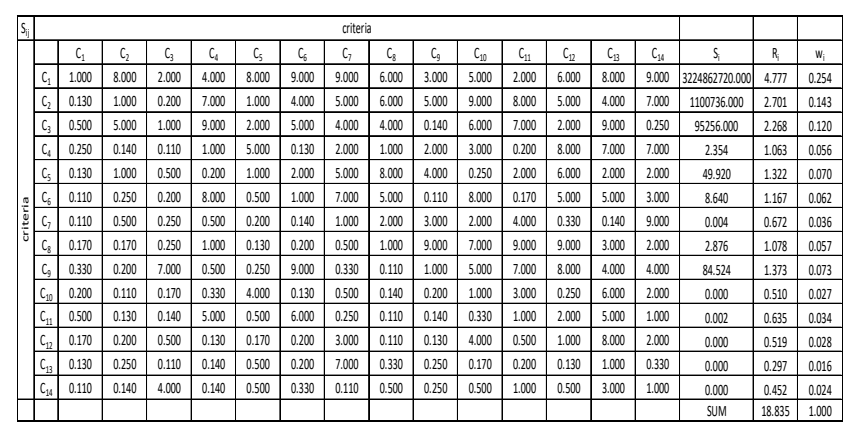

Source: own processing

From Table 2 that express Saaty matrix, it is obvious that for example criteria $\mathrm{C}_{2}$ had been strongly preferred before criteria $\mathrm{C}_{9}$, which means that matrix element $S_{2,9}$ has a value 5. The value that expresses integral in Saaty matrix, on the other side of the diagonal, will present reverse values. The defined element of Saaty matrix that is expressed under given diagonal as $\mathrm{S}_{2,9}$ will be under diagonal as:

$$
\mathrm{S}_{9,2}=1 / 5=0,2
$$

By using formula (1), which expresses the normalized geometric average of rows in the given matrix, which is mentioned in the methodology, we divided 3 partial parts that are consequently used. Formula (2) is used first of all for the calculation of $\mathrm{S}_{\mathrm{i}}$. It presents the multiplication of all elements in the given i-row. Then the calculation of $S_{1}$ is as follows:

$$
\begin{gathered}
\mathrm{S}_{1}=1.00 \times 8.00 \times 2.00 \times 4.00 \times 8.00 \times 9.00 \times 9.00 \times \\
6.00 \times 3.00 \times 5.00 \times 2.00 \times 6.00 \times \\
\times 8.00 \times 9.00=3224862720
\end{gathered}
$$

Consequently, formula (3) is used, which presents the second part of formula (1) dividing for a normalized geometric average of matrix rows. After the application of given formula, we calculated values $R_{i}$, where $S_{i}$ of the given row are exponentiated by rate 1 in a numerator and number of criteria in a denominator, which is, in this case, 14. Through the mentioned the first matrix row will be as follows:

$$
\mathrm{R}_{1}=s_{1} \frac{1}{14}=3224862720^{1 / 14}=4.777265
$$

Similarly, we processed during calculation in any row of Saaty matrix. Final calculation is done according to the third partial calculation from divided formula (1). It means we made rate between $R_{i}$ from the given row in the numerator, for which weights values are calculated, and multiplication of all elements $R_{i}$ in the denominator. According to the mentioned we made calculation for $\mathrm{w}_{1}$ :

$$
w_{1}=\frac{R_{1}}{\sum R}=\frac{4.777}{18.835}
$$

Similar calculation had been done also for other rows of Saaty matrix. The sum of all weights w has to be equal 1. According to the previous Table 2 weights of individual criteria are known. Criteria had been created according to the subjective estimations during visitation of individual operations. The weights of the criteria are determined in last column of the Table 2. According to the mentioned we can state the most important criteria that is products quality $\left(\mathrm{C}_{1}\right)$, while the least important criteria is availability and transport $\left(\mathrm{C}_{13}\right)$. From calculated weights of criteria, we can say that if we change the weight to percentage expression by $100 \%$ multiplication, first 3 criteria should present $51 \%$, from total number of weights. This means the most important criteria are mainly 3 criteria $-\mathrm{C}_{1}-$ products quality, $\mathrm{C}_{2}$ - freshness of the products, $\mathrm{C}_{3}-$ security of the products.

Through Saaty matrix we determined the weights of individual criteria that are used during TOPSIS method. According to the method we created order of individual operations and most convenient operation had been determined from all analyzed services. To realize TOPSIS method, it is necessary to create a matrix, when individual columns will present criteria, marked as $\mathrm{C}_{1}-\mathrm{C}_{14}$ and individual rows will present individual operations $\mathrm{P}_{1}-\mathrm{P}_{16}$ of the company $\mathrm{ABC}$, ltd.

\section{Table 3. Criteria matrix}

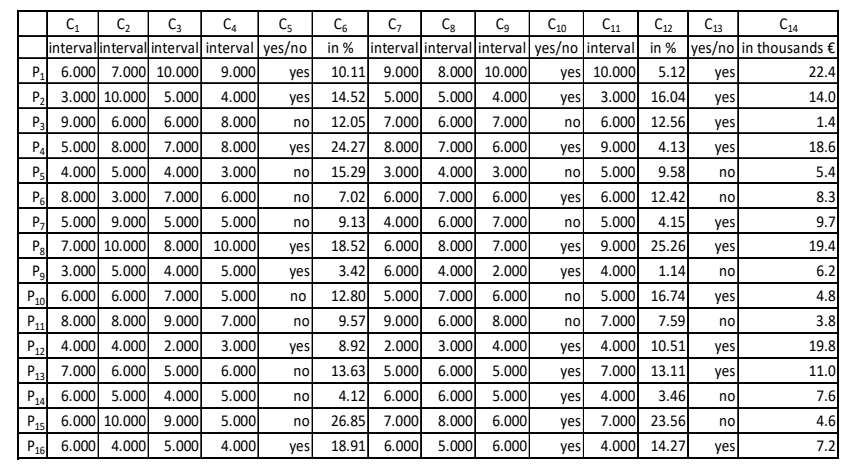

Source: own processing

Values in Table 3 had been obtained as a base from the manager of $\mathrm{ABC}$, 1td. Company, which provides distribution in whole eastern Slovakia. Given operations can be evaluated according to the criteria in interval $\langle 1 ; 10\rangle$, while for criteria $\mathrm{C}_{6}$ - number of clients complaints from total purchased volume of goods in 2019 and $\mathrm{C}_{12}$ - number of complaints is value, mentioned in the table as percentage expression from total purchased volume of goods in 2019, criteria $\mathrm{C}_{14}$ - an advertisement and marketing 
is expressed per months in thousand Eur. Similarly criteria $\mathrm{C}_{5}$ - the flexibility of orders and demand of client, $\mathrm{C}_{10}$ - possibility to pay by card and $\mathrm{C}_{13}-$ availability and transport are recorded by words "yes or no". Since in the matrix there is necessary to express individual values by numbers, in the study we determine "yes" would mean 10 and "no" would present numerical value 0 . According to the mentioned input matrix would be as follows:

\section{Table 4. Input matrix}

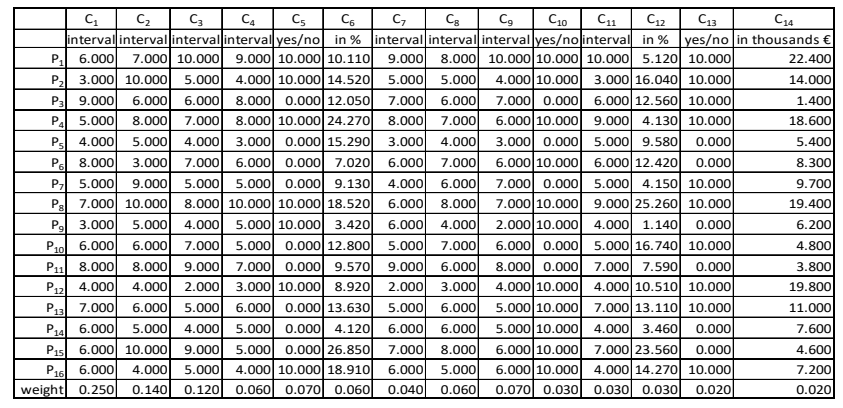

Source: own processing

The input matrix for further calculation is characterized in Table 4. Individual columns present criteria $\left(C_{1}-C_{14}\right)$, for individual operations $\left(P_{1}-P_{16}\right)$. At the same time last row express the weight that had been obtained by Saaty matrix.

\section{Table 5. Normalized criteria matrix}

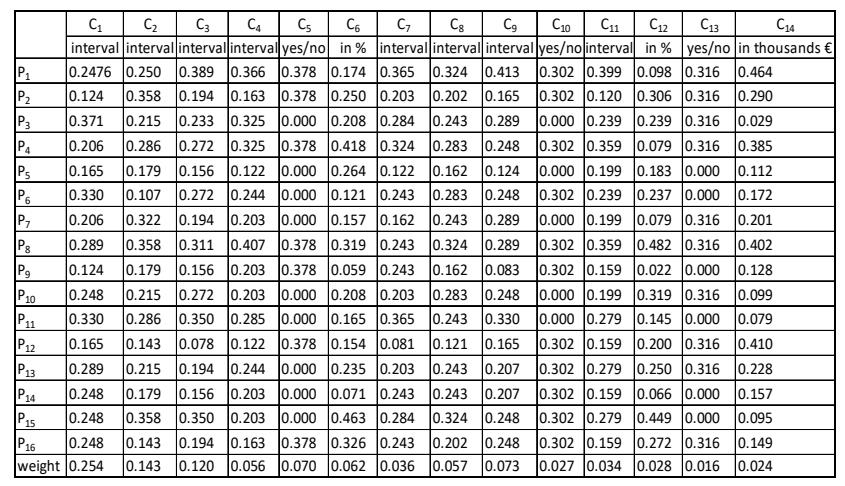

Source: own processing

Through TOPSIS method there had been created normalized criterial matrix $R$, presented in Table 5 . In the table there is applied calculation (13). First of all, we calculated sum of squared of individual criteria for all operations: $\sum_{i=1}^{m} a_{i j}^{2}$ and lately the sum of all elements according the main criteria is square rooted. By square root individual $a_{i j}$, are divided in any operation. For better illustration we mention an example for first criteria in fist operation in Prešov

$r_{i j}=\frac{6.00}{587.00}$. Similar calculation is used for calculation of all values in the matrix and by this way we obtain normalized criteria matrix.

Individual values in Table 5 are multiplied by weight $W_{j}$, which had been obtained according to the calculation in Saaty matrix. From the calculated values the values with highest (ideal) number are selected, but also the values with lowest (basic) number, marked as $V j+$ and $V j-$. Such values are distracted from individual values that are achieved in individual operations during evaluation of given criteria. After determination of the variants there is calculated distance between individual variants from ideal one, and at the same time there is calculated also distance of individual variants from basic one.

In Table 6 there is illustrated calculation of individual ideal and basic variants, marked as $d+$ and $d$-. To make illustration of the calculation better, we mentioned calculation for $d+$ in first operation.

$$
\mathrm{di}+=\sqrt{\begin{array}{c}
(0.06281-0.09422)^{2}+(0.0359-0.051284)^{2}+ \\
+(0.0468-0.046835)^{2}+(0.0207-0.022947)^{2}+ \\
+(0.0265-0.026533)^{2}+(0.0108-0.025906)^{2}+ \\
+(0.0130-0.013026)^{2}+(0.0185-0.018545)^{2}+=0.0396 \\
+(0.0301-0.030111)^{2}+(0.0082-0.008166)^{2}+ \\
+(0.0134-0.013443)^{2}+(0.0027-0.013272)^{2}+ \\
+(0.0050-0.004992)^{2}+(0.0111-0.011117)^{2}
\end{array}}
$$

Similarly, we will continue with other calculations of ideal variants. The basic variant is calculated similarly, while we will extract the lowest basic values among all. At the same time in following Table 6 there is determined closeness of the coefficient of any alternative through formula (19). For the better illustration of the formula the calculation in first operation is as follows:

$$
C C_{i}=\frac{0.0698}{0.0698+0.0396}=0.6378
$$

Individual values are illustrated in Table 6 .

Table 6. Distances of variants from ideal and basic

\begin{tabular}{|c|c|c|c|c|c|c|c|c|c|c|c|c|c|c|c|c|c|}
\hline & $c_{1}$ & $c_{2}$ & $c_{3}$ & $c_{4}$ & $c_{5}$ & $c_{6}$ & $c_{7}$ & $C_{8}$ & $C_{9}$ & $C_{10}$ & $c_{11}$ & $C_{12}$ & $C_{13}$ & $C_{14}$ & \multirow[t]{2}{*}{$d+$} & & \multirow{2}{*}{$\mathrm{Cci}$} \\
\hline & interva & alinterva & interval & alinterva & $5 / 100$ & in $\%$ & interval & interval & interval & yes/no & interval & in $\%$ & yes/no & in thousands & & & \\
\hline & 0.063 & 0.036 & 0.047 & 0.021 & 0.027 & 0.011 & 0.013 & 0.019 & 0.030 & 0.008 & 0.013 & 0.003 & 0.005 & 0.011 & 0.040 & 0.070 & 0.638 \\
\hline & .031 & - & 023 & 0.009 & 0.027 & 0.016 & 0.007 & .012 & 0.012 & 0.008 & 0.004 & 0.008 & 0.005 & 10.00 & 0.073 & 0.051 & 0.411 \\
\hline$p_{z}$ & 4 & 331 & 228 & 0.018 & 0.000 & 13 & 0.010 & 0.014 & 0.021 & 0.000 & 0.008 & 0.007 & 0.005 & 0.001 & 45 & 0.072 & 0.615 \\
\hline$P_{4}$ & 0.052 & 0.041 & 0.033 & 0.018 & 0.027 & 0.026 & 0.012 & 0.016 & 0.018 & 0.008 & 0.012 & 0.002 & 0.005 & 0.009 & {$[0.049$} & 0.059 & 0.550 \\
\hline$P_{5}$ & 0.042 & 0.026 & 0.019 & 0.0069 & 0.000 & 0.016 & 0.004 & 0.009 & 0.009 & 0.000 & 0.007 & 0.005 & 0.000 & 0.00 & 0.078 & 0.023 & 0.224 \\
\hline$P_{6}$ & 0.084 & 0.015 & 0.033 & 0.014 & 0.000 & 0.007 & 0.009 & 0.016 & 0.018 & 0.008 & 0.008 & 0.007 & 0.000 & 0.00 & 0.055 & 0.061 & 0.526 \\
\hline$P_{7}$ & 0.052 & 0.046 & 0.023 & 0.011 & 0.000 & 0.010 & 0.006 & 0.014 & 0.021 & 0.000 & 0.007 & 0.002 & 0.005 & 0.0 & 0.062 & 0.045 & 0.417 \\
\hline$P_{8}$ & 0.073 & 0.051 & 0.037 & 0.023 & 0.027 & 0.020 & 0.009 & 0.019 & 0.021 & 0.008 & 0.012 & 0.013 & 0.005 & 0.01 & 0.026 & 0.077 & 0.747 \\
\hline$p_{9}$ & 0.031 & 0.026 & 0.019 & 0.011 & 0.027 & 0.004 & 0.009 & 0.009 & 0.006 & 0.008 & 0.005 & 0.001 & 0.000 & 0.0 & 0.084 & 0.032 & 0.277 \\
\hline$P_{10}$ & 0.063 & 0.031 & 0.033 & 0.011 & 0.000 & 0.013 & 0.007 & 0.016 & 0.018 & 0.000 & 0.007 & 0.009 & 0.005 & 0.00 & 0.055 & 0.047 & 0.463 \\
\hline$P_{11}$ & 0.084 & 0.041 & 0.042 & 0.016 & 0.000 & 0.010 & 0.013 & 0.014 & 0.024 & 0.000 & 0.009 & 0.004 & 0.000 & 0.00 & 0.040 & 0.072 & 0.643 \\
\hline$P_{12}$ & 0.042 & 0.021 & 0.009 & 0.007 & 0.027 & 0.010 & 0.003 & 0.007 & 0.012 & 0.008 & 0.005 & 0.006 & 0.005 & 0.010 & 0.080 & 0.033 & 0.296 \\
\hline$P_{13}$ & 0.073 & 0.031 & 0.023 & 0.014 & 0.000 & 0.015 & 0.007 & 0.014 & 0.015 & 0.008 & 0.009 & 0.007 & 0.005 & 0.005 & 0.052 & 0.052 & 0.500 \\
\hline$P_{14}$ & 0.063 & 0.026 & 0.019 & 0.011 & 0.000 & 0.004 & 0.009 & 0.014 & 0.015 & 0.008 & 0.005 & 0.002 & 0.000 & 0.004 & 0.065 & 0.038 & 0.368 \\
\hline$P_{15}$ & 0.063 & 0.051 & 0.042 & 0.011 & 0.000 & 0.029 & 0.010 & 0.019 & 0.018 & 0.008 & 0.009 & 0.012 & 0.000 & 0.002 & 0.046 & 0.068 & 0.594 \\
\hline$P_{16}$ & 0.063 & 0.021 & 0.023 & 0.009 & 0.027 & 0.020 & 0.009 & 0.012 & 0.018 & 0.008 & 0.005 & 0.008 & 0.005 & 0.004 & 0.055 & 0.050 & 0.476 \\
\hline$v_{i}^{+}$ & 0.094 & 0.051 & 0.047 & 0.023 & 0.027 & 0.026 & 0.013 & 0.019 & 0.030 & 0.008 & 0.013 & 0.013 & 0.005 & 0.011 & & & \\
\hline v & 0.031 & 0.015 & 0.009 & 0.007 & 0.000 & 0.004 & 0.003 & 0.007 & 0.006 & 0.000 & 0.004 & 0.001 & 0.000 & 0.00 & & & \\
\hline
\end{tabular}
variant

Source: own processing

The next illustrated graph shows resulting values of all criteria. Graph No 1 enables to see difference in individual operations and to help determination of most effective operation among all analyzed ones. 


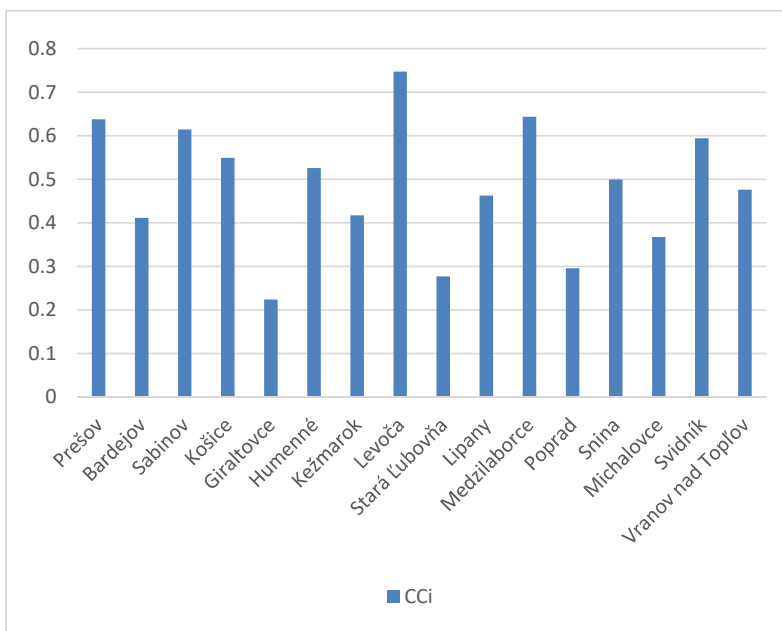

Figure 1. Ranking of individual operations in chosen towns (Source: own processing)

From Figure 1 there is obvious the best evaluated operation is in Levoča. Similarly, the figure illustrates that some smaller towns, as for example Lipany, Svidník, Medzilaborce or Sabinov achieve better values than in bigger town Poprad. From the results we can state that individual employee can manage the operations better than employee in bigger ones. At the same time it can be caused by number of clients. Big number of clients causes the manager, and employees in individual bigger operations are not able to provide comfort in comparing wih smaller operations. With the aim to improve evaluation of operations manager should provide, for example, better rewarding of employees to be orientated more to the proper activity of given operations. By this way, also motivation of employees in individual operations can be increased.

To make clear illustration of volume of given towns, Figure 2 illutrates density of inhabitants (persons per $\mathrm{km}^{2}$ ).

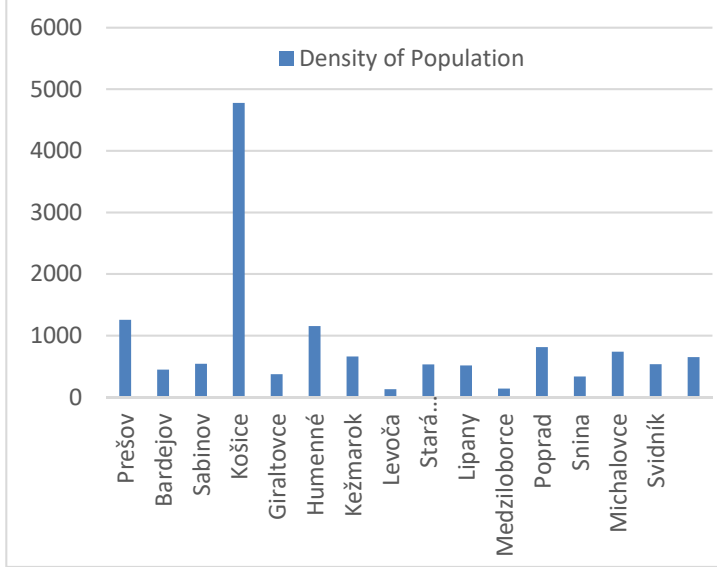

Figure 2. Density of population in chosen towns Source: own processing according to datacube.statistics.sk

Figure 2 illustrates density of inhabitants in individual towns, in which individual operations had been analyzed. Density of population presents statistical index that expresses the rate of inhabitants' number per area of the locality. According to the figure it is obvious that in bigger towns there is achieved also lower performance of the operation in comparing with lower towns. For example, in Košice, where density of population presents yet 4778.37 inhabitants per $\mathrm{km}^{2}$, calculated performance of the operation is 0.549673 . On the other hand, in Levoča, presenting population density 128.43 inhabitants per $\mathrm{km}^{2}$, and coefficient closeness of any alternative is 0.747317 . The value is then higher yet by 0.197644 . In case if we change the values to percentage, the difference would be yet by $20.00 \%$.

\section{Discussion}

Results that are obtained by Saaty matrix and TOPSIS method provide better view to the individual operations of $\mathrm{ABC}$, ltd. Company. From resulting figure it is obvious that the lower operations record better results in comparing with bigger towns. This can be caused mostly by employees that have more jobs and more clients in bigger towns in comparing with smaller towns. Individual results can be influenced by criteria selection and subjective estimation of the decider that evaluated the criteria during purchase in individual operations. Criteria are selected by the way which is not to be orientated only to the goods in given operations, but also all the surrounding perceptions, as for example parking, availability, advertisement or barrier free access. Similarly, the results can be influenced also by subjective opinion of the manager for operations in eastern Slovakia; despite he made evaluation objectively. Obtained results can provide good operation in $\mathrm{ABC}$, ltd. Company with an effort to improve performance of operations in eastern Slovakia. Measurements should be orientated to the motivation of employees, mainly by the way of rewarding. Consequently, more proper repeated research should be done, when according to the further study and questionnaire research the evaluation of analyzed operations could be improved or worsened. It could provide complex opinion of clients to given operation.

\section{Conclusion}

In the contribution, three methods are applied for evaluation of company performance, mainly: Saaty matrix, FUZZY AHP and TOPSIS method. The methods are applied in the example through Saaty matrix, when individual weights are determined for given criteria. Consequently a TOPSIS method is used as well, through which there is determined ideal and basic variant and then distance from these variants is calculated. The last step in TOPSIS method is determination of coefficient closeness of any alternative. By this way there is created order of individual operations of analyzed company. With the aim to create idea of inhabitants' number in analyzed operations in eastern Slovakia, there is also graphically illustrated population density in given town of analysis. The data are obtained from statistical office of Slovakia. Chosen operations should achieve positive results if any operation would be unique and extraordinary. Results of the 
study show that the operations in towns with lower number of inhabitants record better results in comparing with operations in towns with higher population density. Such results can be signal for managers to orientate operations in bigger towns. Mentioned study is realized according to the expert estimation and evaluation of managers for eastern Slovakia. In the future research there would be proper to extend the study by broad spectral scale of clients' opinion and by this way to extend subjective view of manager to determined operations. Objective opinion of clients could contribute to the achievement of better determination and evaluation of criteria. During determination of clients' weights to given criteria, the study should lead to more detail and more real views with regard to clients, which could state new hypothesis of the problematic .

\section{Acknowledgment}

The contribution was addressed within the Young Researchers and Doctoral Students Project, number I-21103-00 Impact of the COVID-19 pandemic on the evaluation of the financial performance of small and medium-sized enterprises within the V4 countries from an accounting and tax point of view.

\section{References}

[1]. Idowu, A. J., Iledare, O. O., \& Dada, B. G. (2019). Evaluating Technical Efficiency of Firms of Different Sizes: A Case Study of Nigerian Upstream Players. SPE Reservoir Evaluation \& Engineering, 22(02), 775-788.

[2]. Wang, Q., Wang, H., Gupta, C., Rao, A. R., \& Khorasgani, H. (2020, December). A Non-linear Function-on-Function Model for Regression with Time Series Data. In 2020 IEEE International Conference on Big Data (Big Data) (pp. 232-239). IEEE. DOI: 10.1109/BigData50022.2020.9378087

[3]. Sorenson, G. E., \& Lavelle, J. P. (2008). A comparison of fuzzy set and probabilistic paradigms for ranking vague economic investment information using a present worth criterion. The Engineering Economist, 53(1), 42-67.

[4]. Kuchta, D. (2001). A fuzzy model for R\&D project selection with benefit, outcome and resource interactions. The Engineering Economist, 46(3), 164180.

[5]. Omitaomu, O. A., \& Badiru, A. (2007). Fuzzy present value analysis model for evaluating information system projects. The Engineering Economist, 52(2), 157-178.

[6]. Ergu, D., Kou, G., Peng, Y., \& Shi, Y. (2011). A simple method to improve the consistency ratio of the pair-wise comparison matrix in ANP. European Journal of Operational Research, 213(1), 246-259.

[7]. Krejčí, J., Pavlačka, O., \& Talašová, J. (2017). A fuzzy extension of analytic hierarchy process based on the constrained fuzzy arithmetic. Fuzzy Optimization and Decision Making, 16(1), 89-110.
[8]. Ramík, J., \& Korviny, P. (2010). Inconsistency of pair-wise comparison matrix with fuzzy elements based on geometric mean. Fuzzy Sets and Systems, 161(11), 1604-1613.

[9]. Ramík, J. (2018). Strong reciprocity and strong consistency in pairwise comparison matrix with fuzzy elements. Fuzzy Optimization and Decision Making, 17(3), 337-355.

[10]. Cavallo, B., \& D'Apuzzo, L. (2009). A general unified framework for pairwise comparison matrices in multicriterial methods. International Journal of Intelligent Systems, 24(4), 377-398.

[11]. Mazurek, J., \& Ramík, J. (2019). Some new properties of inconsistent pairwise comparisons matrices. International Journal of Approximate Reasoning, 113, 119-132.

[12]. Hoang, L.K., \& Nguyen, K.T. (2020). Fuzzy-AHP application in analyzing the factors affecting quality of rural labor. Journal of Asian Finance, Economics and Business, 7(8), 715-721.

[13]. Brotons, J. M., \& Sansalvador, M. E. (2017). A fuzzy model for the quantification of cost of quality based on the aggregation of information. Fuzzy Economic Review, 22(1), 33-44.

[14].Wang, Z. J. (2019). An axiomatic property based triangular fuzzy extension of Saaty's consistency. Computers \& Industrial Engineering, 137, 106086.

[15]. Bernasconi, M., Choirat, C., \& Seri, R. (2010). The analytic hierarchy process and the theory of measurement. Management Science, 56(4), 699-711.

[16]. Saaty, T. L. (1996). Decision making with dependence and feedback: The analytic network process (Vol. 4922, No. 2). Pittsburgh: RWS publications.

[17] Lomakin, V. V., Putivtseva, N. P., Zaitseva, T. V., Liferenko, M. V., \& Zaitsev, I. M. (2017). Multicritera selection of a corporate system by using paired comparison analysis. Journal of Fundamental and Applied Sciences, 9(7S), 1472-1482.

[18]. Roháčová, I., \& Marková, Z. (2009). Analýza metódy AHP a jej potenciálne využitie V logistike. Acta Montanistica Slovaca, 14(1), 103-112.

[19]. Fiala, P. (2013). A Hybrid Procedure for Network Multi-Criteria Systems. Acta Universitatis Palackianae Olomucensis. Facultas Rerum Naturalium. Mathematica, 52(2), 53-60.

[20]. Duman, G. M., Tozanli, O., Kongar, E., \& Gupta, S. M. (2017). A holistic approach for performance evaluation using quantitative and qualitative data: a food industry case study. Expert systems with applications, 81, 410-422.

Doi: 10.1016/j.eswa.2017.03.070

[21]. Yoon, K. P., \& Hwang, C. L. (1995). Multiple attribute decision making: an introduction. Sage publications.

[22]. Triantaphyllou, E. (2000). Multi-criteria decision making methods. In Multi-criteria decision making methods: A comparative study (pp. 5-21). Springer, Boston, MA. 